\title{
Digital ecology: Artificial intelligence impact on legal and environmental sphere
}

\author{
Vasiliev A.A. ${ }^{1}$, Pechatnova Y.V. ${ }^{1}$, Mamychev A.Yu. ${ }^{2}$ \\ ${ }^{1}$ Altai State University, Public University in Barnaul, Russia \\ ${ }^{2}$ Vladivostok State University of Economics and Service, University in Vladivostok, Russia
}

Corresponding author E-mail: anton-vasiliev@mail.ru

Received: 08.09.2020. Accepted: 25.10.2020

\begin{abstract}
New century turns out the intensive scientific revolution, which leads to the extension the digital technologies. The research is devoted to the analysis the opportunities and prospects for the implementation of the artificial intelligence in the legal system. The urgency of the study predetermines by the large-scale digital revolution that affects all spheres of society, including the area of legal activity (for example, the initiative to use lawyers-robots in the legal corporations; the idea to automate legal activity; the appearance of smart contracts, blockchain technologies, cryptocurrency, which are not regulated by the Russian law yet; increase if the cybercrime and others). The purpose of the study is to analyze the advantages and disadvantages, opportunities and limits of introducing the digital technologies into the legal environment. Research methods are analysis, synthesis and comparative law. The study contains several positions. Firstly, the analysis the points of view about the theme of research among the national and foreign scientists are presented. Secondly, the comprehensive assessment of the artificial intelligence influence on the legal sphere is given. Thirdly, the opportunities for regulation changed relationships, connected with digital technologies, in the current Russian legislation, and the advantages and disadvantages of fixing new categories in the Civil Code of the Russian Federation are researched. Fourthly, examples of the negative impact of legal vacuum on the law enforcement practice and the ways for its overcoming are given. By the way, specific decisions of the courts given as the arguments. Fifthly, the analysis of current trends in the introduction of digital technologies in the legal sphere in the Russian Federation and in the over countries is carried out. There are some contradictory opinions of scientists and practitioners regarding the possibility of using robotic technologies in the legal system. Sixthly, it presents own conclusion based on the conducted research, which is to substantiate the positive trend towards digitalization in the legal system, but the negativity of the possible effects excessive interference of the artificial intelligence in the legal activity.
\end{abstract}

Keywords: Digital ecology; Environmental; Digital law; Legal regulation; Artificial intelligence; Cyberspace; Robots; Cryptocurrency

\section{Introduction}

The development of the artificial intelligence leads to the significant transformation in the whole social sphere. Undoubtedly, artificial intelligence becomes the indicator of success and permeates much of modern business, because it is rapidly becoming the powerful tool of innovation. Firstly, W. Michael Schuster researches the problems of interaction between the artificial intelligence and patent ownership, whose cooperation leads to maximize economic efficiency, but face to legal problems (Schuster, 2018).

Secondly, the research work of W. Nicholson Price II describes the concept of artificial intelligence in medicine, including several possible applications, and then considers its legal implications in four areas of law: regulation, tort, intellectual property, and privacy. But he also points legal obstacles for full implementation of such technologies (Price, Nicholson, 2017). As a result, the international scientific community is rapidly filling the legal vacuum, which hinders technological progress implementation. There are lots of model projects of legal acts, which are regulating the creation and use of digital technologies, now. In the countries, where digital technologies are most actively using, the legal conditions for the use of artificial intelligence are just as actively created. South Korea became one of the pioneers in this field. In 2008 the Law, which was devoted the promotion of development and distribution of smart robots, was adopted in this country.

In 2012, the European Commission launched the RoboLaw project (Regulating, 2020), whose main goal was the establishment an appropriate legal environment for the development of robotic technologies in Europe. In the United Arab Emirates, the Ministry of Artificial Intelligence was created for the first time in the world. In 2017, the Strategy for Artificial Intelligence was adopted here. It was aimed to implementation the artificial intelligence in the field of transport, education, space, production. Estonia became the first country in the world, which legalizes the rules for robots movement. Japan, which secured its status as the leading robot power, approved the five-year "New Robot Strategy" in 2015 (National Research, 2019).

In Russia, the Research Center for the Regulation of Robotics and Artificial Intelligence (Research Center, 2019) proposed the Model Convention "Rules for the Creation and Use of Robots and Artificial Intelligence". The document proposes the rules for the development, creation, use the robots of all categories, despite their purpose, degree of danger, mobility or autonomy. The Convention aims to combine the main approaches to regulation and initiate the adoption of the first international act in this area. However, despite the qualitative content, the Convention remained the declarative model project. 
These are the first steps, which are undertaken by the lawyers all over the world. At the same time, it has to be confessed that the legal regulation of this sphere remains as a vacuum. The main causes are: contradictions between the liberty, immunity, inviolability and other constitutional rights and boundless opportunities of artificial intelligence. Thus, the purpose of this research is the analysis of permissible limits of artificial intelligence implementation and its effect of digital ecology.

\section{Materials and Methods}

There are some directions of the research: robots in the legal sphere, regulation of cryptocurrency exchange and the legal regulation of smart contracts. Firstly, it should be pointed that the popular tend is: robots will replace lawyers in the nearest future. So, there is an indisputable argument in favor of this thesis. In Great Britain, the system with artificial intelligence - Smartsettle ONE - has been already developed. This is the kind of mediator-robot that is able to build the negotiation tactics of the parties to achieve the optimal agreement.

In 2019 , for the first time in the history of civil proceedings, the dispute between the parties was settled in pre-trial procedure by the mediator-robot. By the way, the robot solved the problem for which the person used three-month negotiations in one hour. Thus, the introduction of artificial intelligence in legal proceedings involves the significant reduction in the burden on the judiciary, increasing the efficiency of the administration of justice, overcoming the problems of judicial red tape and corruption (Robot mediator, 2019). Also in Great Britain the model program has been created that can predetermine decisions of the European Court of Human Rights. It is known that the European Court of Human Rights has strict requirements for compliance with formal criteria for filing and processing complaints. It was not difficult for programmers to algorithmize this set of formal criteria. As a result, out of 584 appeals to the ECHR, the decision on consideration of appeals made by the program in $79 \%$ of cases coincided with the court decision.

In the Russian Federation attempts to organize the debate between the robot and the human are being made. Despite the fact that robot's opponent R.S. Bevzenko won the dispute with the robot-lawyer, he praised the skill of legal thinking of the bot. For the first time, the robot showed excellent results, confirming the potential, prospects and the real possibility of introducing robot-lawyers (The legal, 2019). Thus, if the category "judge-robot" still seems to be a vast future, then the category "lawyer-robot" takes on more and more visible outlines. Widespread are online platforms that specialize in providing consumers with legal services using information technology. Examples of such resources: projects that offers lawyers to create their own legal bots to automate routines; resources, equipped with the ability of the robot to independently answer typical questions; application that allows to create contracts yourself, without resorting to a lawyer and changes the principle of concluding contracts; resource for automatically preparation the standard complaints for typical situations and others.

It should be also mentioned that in the Russian judicial practice, there are practically no cases involving robots due to the uncertainty of their legal status. In foreign scientific papers there is the proposal to give robots an independent status of an "electronic person", along with individuals and legal entities. However, the majority of Russian theorists and practitioners tend to endow the rights, duties and responsibilities of not the robot, but its owner. This view is held by the judicial practice.

The judicial case, in which the participant is robot, connects with the Google's lawsuit over company's privacy violation. So, while reading personal e-mail, the mail user (Claimant) found that the advertising slogans embedded in the text of the letter correspond to the content of his correspondence. It turned out that the Respondent reads correspondence using robots to place advertisements in letters corresponding, That is why, the content of the letter conform to the advertisements content. Thus, by his actions, the Respondent violates the constitutional right to privacy and confidentiality of correspondence.

First court decision bases more on that the jurisdiction of the lawsuit against the foreign corporation. So, the trial court pays little attention to the issue of violating the secrecy of correspondence by robots. The appellate court upholds the plaintiff's claim and prohibited Google from reading personal correspondence through the use of robots (Google Appealed, 2020). Thus, the robot on its own turns out of the legal field. Responsibility for the offence can be shared between producer and exploiter of the robot.

Secondly, the Russian arbitrage practice, connected with legal regulation of the cryptocurrency, is more various than the legal regulation of robotization. So, on May 15, 2018, the Russian Ninth Arbitration Court of Appeal for the first time in judicial practice qualified cryptocurrency as property. By the decision of the court of first instance, the financial manager was denied the requirement to include the contents of the crypto wallet in the bankruptcy estate of the citizen - the debtor and the obligation of the citizen - debtor to transfer access to the crypto wallet to the financial manager (transfer the password). The court of first instance proceeded from the fact that cryptocurrency does not apply to objects of the Russian civil rights. So, the cryptocurrency is located outside the legal field on the territory of the Russian Federation, transactions with cryptocurrency, its transactions are not provided by the compulsory force of the state. The absence of the controlling center in the cryptocurrency system and the anonymity of cryptocurrency users, in the court's opinion, does not allow us to determine with certainty whether the cryptocurrency belongs to the specific person in the cryptocurrency wallet.

The Russian Ninth Arbitration Court of Appeal concluded that the decision of the court of first instance is illegal. The court considers that, due to the dispositive nature of civil law, the Civil Code of the Russian Federation does not have the closed list of the objects of civil law. Since the current Russian civil law does not contain the concept of "other property", taking into account modern economic realities and the level of development of information technologies, widest interpretation of this term is permissible.

According to the decision of the Russian Appeal court, cryptocurrency should be regarded as other property (The resolution, 2018). The next object for research is the decision of the Ryazhsky District Court of April 26, 2017. The plaintiff transferred the cryptocurrency to the wallet of the "online exchanger", in order to exchange cryptocurrency for rubles at the exchange rate indicated on the website of the "online exchanger". Rubles must be transferred by bank transfer to the plaintiff's account. However, the amount was not transferred in full. The reasoning part of the court decision states that since practically in the Russian Federation there is no legal basis for regulating payments made in" virtual currency ", in particular, Bitcoin, and there is no legal regulation of trading Internet sites, bitcoin- exchanges, all operations involving the transfer of bitcoins are carried out by their owners at their own risk. So, the "Claimant", agreed to the terms of the provision of electronic currency exchange services, assumed the risk of any financial loss and/or damage that might have been caused to him as a result of the delay or inability to make electronic transfers. That is why, the Russian court considers insolvent the plaintiff's arguments that the indicated has violated his rights. By the way, the presence of cryptocurrencies outside the legal field does not provide the possibility for the plaintiff to implement the legal mechanisms for imposing liability on the defendant in the form of payment by the latter of the penalty, compensation for moral damage and the fine provided by the Law on Protection of Consumer Rights (Decision, 2017). So, in the period from January 1, 2009 to November 20, 2017, courts of general jurisdiction prepared the total of 46 court decisions on the subject of cryptocurrencies. There is one judgment of the Intellectual Property Rights Court. However, 43 out of 46 court decisions 
relate to blocking resources on the Internet due to the dissemination of information containing advertising of services and services related to cryptocurrencies (Avakian et al., 2018). According to the report of the Forensic Expertise Center RTM Group (the group of expert law firms specializing in legal and technical issues in the field of information technology and information security), enforcement statistics show that it is impossible to protect the interests of individuals who invest or use cryptocurrencies due to the lack of legal regulation of cryptocurrencies in the Russian Federation.

Thus, judicial practice indicates that legal regulation of a transformed financial market without an appropriate update of legislative provisions is ineffective. Today, diametrically opposite models of legal regulation have formed - from the complete ban on cryptocurrencies to giving them the status of an official means of payment. The gradual spread of litigation related to the circulation of cryptocurrencies confirms the urgent need for normative consolidation of the status of cryptocurrencies. Thirdly, researching the formation of contracts in open electronic networks becomes very popular. The open electronic networks create the new transacting environment, which modifies the features of contractual intention and put strain on traditional analytical models. Contract law evolved on such basis as the model of face-to-face communications between humans and the existence of tangible carriers. Instead of it, open electronic networks encounters numerous difficulties new problems, which have no equivalents and which do not easily fit in the framework of traditional legal institutions.

Firstly, it is the lack of tangible carriers and the fact that interactions over open electronic networks are the hybrid between conduct, writing and electronic documents. Secondly, it is the fact that contractual statements are not only transmitted but also processed by various intermediating systems and the system of the addressee. This results in a number of inherent risks, which must be allocated using traditional principles. Thirdly, there is hype. The impact of certain technologies is being overstated while the importance of others is being played down or ignored. These results in misplaced focus: much legal analysis was devoted to so-called digita signatures and their role in fulfilling formal requirements. Little attention was directed to the contractual implications of hypertext or how differences between network environments affect the ability to communicate intention (Mik, 2007).

\section{Results and Discussion}

Robotisation, cryptocurrencies exchange, smart contracts are the effects of artificial intelligent implementation in the social sphere and the challenge for legal science. The results of study these three objects shows the problems in their legal realization. Robots are the indefinite subject of the legal relationship. Cryptocurrencies are the indefinite object of the legal relationship. And smart contracts are the indefinite procedure of entry into legal relationship. Thus, the necessarily of legal regulation of these objects is evident. This thesis is confirmed not only the Russian judicial practice, which are presented above, but also the opinions between scientists all over the world. Firstly, unanimously point of view is that robotication is inevitable process. However, this category is ambiguously interpreted in the legal field by different scientists.

Tyler Jaynes suggests the original concept of legal personhood for artificial intelligence, according to which artificial intelligence can possess citizenship with specific civil duties and protections. The author is surprised that the concept of computational artificial artefacts is created, but law makers internationally have come to a standstill to protect our silicon brainchildren. Thus, lots of researches aim to provide international jurisprudence evidence for importance non-biological intelligence protection (Tyler, 2019). Milan Markovic is sure that the advent of artificial intelligence has provoked considerable speculation about the future of the workforce, including highly educated professionals such as lawyers. Although most commentators are alarmed by the prospect of intelligent machines displacing millions of workers, this is not so with respect to the legal sector. Media accounts and some legal scholars envision a future where intelligent machines perform the bulk of legal work, and legal services are less expensive and more accessible. The author challenges the notion that lawyers will be displaced by artificial intelligence. Most legal tasks are inherently abstract and cannot be performed by even advanced artificial intelligence relying on deep-learning techniques. In addition, lawyer employment and wages have grown steadily over the last twenty years, evincing that the legal profession has benefited from new technologies, as it has throughout its history. Lastly, were large-scale automation of legal work possible, core societal values would counsel against it (Markovic, 2019). Ying Hu discusses the responsibility of robots, when a robot harms humans. He suggest that there are any grounds for holding it criminally liable for its misconduct, provided that the robot is capable of making, acting on, and communicating the reasons behind its moral decisions ( $\mathrm{Hu}, 2019)$. If such a robot fails to observe the minimum moral standards that society requires of it, labeling it as a criminal can effectively fulfill criminal law's function of censuring wrongful conduct and alleviating the emotional harm that may be inflicted on human victims. Imposing criminal liability on robots does not absolve robot manufacturers, trainers, or owners of their individual criminal liability.

The former is not rendered redundant by the latter. It is possible that no human is sufficiently at fault in causing a robot to commit a particular morally wrongful action. Additionally, imposing criminal liability on robots might sometimes have significant instrumental value, such as helping to identify culpable individuals and serving as a self-policing device for individuals who interact with robots. Finally, treating robots that satisfy the above-mentioned conditions as moral agents appears much more plausible if we adopt a less human-centric account of moral agency. R.G. Wright also considers that most of the existing discussions of advanced robots as potential rights-bearers focus on the idea of some degree of consciousness, or at best, of self-consciousness with or without a capacity for sentient experience (Wright, 2019). Secondly, the legal regulation of cryptocurrencies is unanimously received by the scientific community. So, at less than a decade old, Bitcoin and other virtual currencies have had the major societal impact, and proven to be the unique payment systems challenge for law enforcement, financial regulatory authorities worldwide, and the investment community. Rapid introduction and diffusion of technological changes throughout society, such as the blockchain that serves as Bitcoin's crypto-foundation, continue to exceed the ability of law and regulation to keep pace. During 2017 alone, the market price of Bitcoin rose $1,735 \%$, from about $\$ 970$ to $\$ 14,292$, causing an investor feeding frenzy. As of September 11,2018 , a total of 1,935 cryptocurrencies are reported, having an approximate market capitalization of $\$ 191.54$ billion at that date. A brief history of the fast moving adoption of blockchain-based technology is provided, along with a look at the efforts of regulators to keep up with the staggering worldwide growth in the usage of virtual currencies (Bitcoin, 2018).

By the why, there are lots of cases, when market participants engage in fraud under the guise of offering digital instruments, especially with the use of virtual currencies. Though, the law enforcement has no opportunity to stop and prevent fraud in the offer and sale of digital instruments. Nima Zahadat points that despite the phenomenal growth in the digital world and crimes committed using digital techniques and tools, there are literally no foundational requirements to perform digital forensic investigations. While there are several private and mostly for-profit organizations that "sell" training and certifications regarding digital forensics credentials, at the international and state level, there seem to be nothing of the kind. However, digital forensic investigation is one of the prominent fields emerging from the broad discipline of forensic science [24]. Thirdly, smart contracts may prove the powerful 
way to license copyright material and to provide higher levels of transparency in financial flows to creators. However, these achievements and the promise they hold are largely dependent on blockchain technologies achieving a degree of development, scalability, reliability and market adoption difficult to foresee at this stage. Still, should blockchain technology reach its market potential, it may have significant-perhaps transformative-impact on copyright in the digital environment (Blockchain, 2018).

Also smart contracts suppose the specific procedure of personal identification. That is why, Lauren Stewart insists on that biometric identification technology is playing an increasingly significant role in the lives of consumers all over the world today. However, despite the benefits of increased data security and ease of consumer access to businesses' services, lack of widespread biometric data regulation creates the potential for commercial misuse. Although some states of the United States of America, such as Illinois, Texas, and Washington, have adopted comprehensive biometric data regulation statutes, the statutes do not offer the consistent approach. Therefore, as more states are going to regulate businesses' collection and use of biometric data, they should enact statutes that seek to balance protecting consumers' biometric data from discriminatory use and businesses' use of biometric data to enhance security and provide improved products and services.

\section{Conclusion}

Human element in the artificial intelligence is above everything else. As Joshua A.T. says, blockchain technologies are about onethird math and two-thirds game theory (Joshua, 2019). The main player in this game is human, and its basic duty - to control the process of challenging game. Our research has shown that new scientific revolution significantly has changed the world. Three results of innovate changes were analyzed: robotisation, cryptocurrencies exchange, smart contracts. Both the Russian judicial practice and the national and international literature were studied. As a result, most scientific opinions support the necessarily of the digital law formation. It means that robots must be regulated as a subject; cryptocurrencies are reflected in the Civil Code as the object of the civil rights; the procedure of the smart contracts realization is also fixed in the Civil Code. By the way, some authors express categorically position about the current state of information technology. Some of them even call that it is time to requiem for cyberspace. Lots of opposite points of view is caused the discussion about the General Data Protection Regulation (GDPR). It is a piece of legislation that was approved by the European Union Parliament in April 2016. It aims to give consumers control of their personal data collected by companies. Not only does it affect organizations located within the European Union, but it also applies to companies outside of the region if they offer goods or services to, or monitor the behavior of, people in the European Union (Avakian et al., 2018).

Scientists express different points. One of them are support such global project. For example, Alex Alben is sure that broad regulatory regimes - such as the European Union's General Data Protection Regulation - will probably have a net positive effect for both freedom and democracy, to the extent that individuals regain control over their personal information and such information becomes less vulnerable to manipulation. Yet the threat will be with us for many years to come; advocates of privacy and democracy must remain vigilant (Alben, 2019).

Others (for instance, S.P. Tapia) - are against. In his opinion, the Internet seemed to be the closest incarnate approximation developed of a dimension beyond the bounds of time, space, and the laws of nature. It is no surprise, therefore, that for almost a quarter of a century, the fear of losing this seemingly limitless and boundless creation has been the primary metaphysical driver of policies and legislation worldwide. In short, for a long time, the governing entities in the world took a "hands-off" approach to regulating this universal construct called "the Internet." However, the General Data Protection Regulation's broad reach has effectively diminished what Internet content is available in the European Union and has made a smaller, European-only Internet. As a direct consequence, the "cyberspace" ideal of a universal place where ideas can be freely exchanged without restriction is dead, and the migration of thoughts, ideas, and viewpoints from outside Europe faces a substantial barrier to entry (Tapia, 2019). Thus, the problem of artificial intelligence implication in the legal sphere is wildly-spread and challenging.

Undoubtedly, the gradual introduction of the latest technologies in legal proceedings and a smooth transition to the digital era is coming. In this regard, it is necessary to establish limits on the digitalization of the legal system, which should be limited to the improvement of electronic codes, the generation of standard court decisions, the creation of an automated system for monitoring judicial practice and other means that will reduce the burden on the legal system, speed up and improve administration of justice, to overcome the problems of judicial red tape and corruption, to reduce the significant burden on the judicial apparatus (Vasilyev et al., 2019). The benefits of spread the information technologies must combine and balance with the constitutional rights.

\section{References}

Alben, A. (2019). Privacy, Freedom and Technology - or "How Did We Get into This Mess?" Seattle University Law Review, 1043-1055.

Avakian, S., Peikin, S., McDonald, J. (2018). U.S. Securities and Exchange Commission, Joint Statement by SEC and CFTC Enforcement Directors Regarding Virtual Currency Enforcement Actions. Available from: https://www.sec.gov/news/public-statement/joint-statement-sec-and-cftcenforcementdirectors?lipi=urn\%3Ali\%3Apage\%3Ad flagship3 feed\%3BpNbaOW7eTJGeW\%2FSWptamAQ\%3D\%3D.

Bitcoin, Virtual Currencies and the Struggle of Law and Regulation to Keep Pace. (2018), 102 Marq. L. Rev. 447. Available from: htts://scholarship.law.marquett.edu/mulr/vol102/iss2/5

Blockchain and smartcontracts: the missing link in copyright licensing? (2018). Oxford, International Journal of Law and Information Technology, 311-336.

Decision No. 2-160/2017. April 26, 2017, case No. 2-160/2017. Available from: http://sudact.ru/regular/doc/qlE6zawJCy6l/ Google Appealed Judicial Prohibition to Robots to Read Letters of Russians. Available from: http://sutyajnik.ru/documents/4894.pdf Hu, Y. (2019). Robot Criminals, 52 U. Mich. J. L. Reform 487. Available from: htts://repository.law.umich.edu/mjlr/vol52/iss2/5

Joshua, A.T. (2019). The Human Element: The Under-Thorized and Underutilized Component Vital to Fostering Blockchain Development, Faculty Scholarship. Available from: htts://scholarlycommons.law.wlu.edu/wlufac/537

Markovic, M. (2019). Rise of the Robot Lawyers?, 61 Ariz. L. Rev. 325. Available from: htts://scholarship.law.tamu.edu/facscholar/1320

Mik, E. (2007). Contract Formation in Open Electronic Networks, Singapore Management University. Available from: htts://works. bepress.com/elizamik/2/

National Research University Higher School of Economics Institute for Statistical Studies and Economics of Knowledge. Available from: https://issek.hse.ru/news/227178200.html

Nima, Z. (2019). Digital Forensics. A Need for Credentials and Standards, Journal of Digital Forensics, Security and Law, 14(1), 3. Available from: htts://commons.erau.edu/jdfsl/vol14/iss1/3

Price, W. Nicholson, II. (2017). Artificial Intelligence in Health Care: Applications and Legal Implications. The SciTech Lawyer 14, 1.

Regulating Emerging Robotic Technologies in Europe: Robotics facing Law and Ethics. Available from: http://www.robolaw.eu/

Research Center for Robotics and Artificial Intelligence Regulation Issues. Available from: http://robopravo.ru/

Robot mediator settles first ever court case. Available from: https://www.legalfutures.co.uk/latest-news/robot-mediator-settles-first-ever-court-case 
RTM technologies. (2019). Available from: http://www.rtm.group/

Schuster, W.M. (2018). Artificial Intelligence and Patent Ownership, 75 Wash. \& Lee L. Rev. $1945 . \quad$ Available from: htts://scholarlycommons.law.wlu.edu/wlulr/vol75/iss4/5

Stewart, L. (2019). Big Data Discrimination: Maintaining Protection of Individual Privacy Without Disincentivizing Businesses' Use of Biometric Data to Enhance Security, 60 B.C.L. Rev. 347. Available from: htts://lawdigitalcommons.bc.edu/bclr/vol60/iss1/8

Tapia, S.P. (2019). Requiem for Cyberspace: The Effect of the European General Privacy Regulation on the Global Internet, Seattle University Law Review, 1163-1173.

The legal personality of artificial intelligence in the field of law. Available from: https://zakon.ru/blog/2018/05/21/kak ya pobedil sudebnogo robota-yurista i pochemu eto budet dlitsya nedolgo\#comment 464411
The resolution of the Ninth Arbitration Court of Appeal. (2018). May 15, 2018. No 09AP-16416/2018. Available from: The resolution of the Ninth Arbitration Court of Appeal. (2018). May 15, 2018. No 09AP-16416/2018. Availab
http://base.garant.ru/61623374/

Tyler, J. (2019). Legal Personhood for Artificial Intelligence. Utah Valley University. Available from: htts://works.bepress.com/tyjaynes/1/ Vasilyev, A.A., Ibragimov, Zh.I., Gubernatorova, E.V. (2019). The Russian draft bill of "the Grishin Law" in terms of improving the legal regulation of relations in the field of robotics: critical analysis. Journal of Physics: Conference Series, 1333(4), Mechatronics, robotics and electrical drives. Doi: $10.1088 / 1742-6596 / 1333 / 5 / 052027$

Wright, R.G. (2019). The Constitutional Rights of Advanced Robots (and of Human Beings), 71 Ark. L. Rev. 613. Available from: htts://scholarworks.uark.edu/alr/vol71/iss3/2

\section{Citation:}

Vasiliev. A.A., Pechatnova. Y.V., Mamychev A.Yu. (2020). Digital ecology: Artificial intelligence impact on legal and environmental sphere. Ukrainian Journal of Ecology, 10(5), 150-154. 